\title{
Severe COVID-19 in Patients with B Cell Alymphocytosis and Response to Convalescent Plasma Therapy
}

\author{
Jonathan London $^{1}$ (D) David Boutboul ${ }^{2,3} \cdot$ Karine Lacombe $^{4} \cdot$ France Pirenne $^{5} \cdot$ Beate Heym $^{6} \cdot$ Valérie Zeller $^{1}$. \\ Antoine Baudet $^{7} \cdot$ Amani Ouedrani $^{8,9} \cdot$ Alice Bérezné $^{7}$
}

Received: 9 July 2020 / Accepted: 28 October 2020 / Published online: 20 November 2020

(C) Springer Science+Business Media, LLC, part of Springer Nature 2020

To the Editor,

The emergence of severe acute respiratory syndrome coronavirus 2 (SARS-CoV-2), which is responsible for coronavirus disease 2019 (COVID-19), has resulted in a global pandemic. In most cases, COVID-19 is a self-limited infection but some patients will present with severe respiratory distress requiring intensive care unit admission and mechanical ventilation. The main risk factors for severe forms are older age, cardiovascular, and chronic pulmonary diseases [1]. The role of primary or acquired immune deficiencies (ID) in the onset of severe COVID-19 is still controversial. This could be explained by the great heterogeneity of ID, with variable risks depending on the ID subtype. The risk of developing a severe form of COVID-19 in patients with primary ID such as common variable immunodeficiency (CVID) or agammaglobulinemia is not known [2], Herein, we describe two patients with hypogammaglobulinemia and $\mathrm{B}$ cell alymphocytosis who presented with severe COVID-19 including a patient with a chronic viremic form that persisted after acute respiratory distress syndrome (ARDS) recovery and successfully treated with convalescent plasma.

Jonathan London

jlondon@hopital-dcss.org

David Boutboul

david.boutboul@aphp.fr

1 Department of Internal Medicine and Infectious diseases, Hôpital Diaconesses Croix Saint-Simon, 125 rue d'Avron, 75020 Paris, France

2 Department of Clinical Immunology, Hôpital Saint-Louis, Assistance Publique Hôpitaux de Paris (APHP), Université de Paris, Paris, France

3 U976 HIPI, Insight team, Hôpital Saint-Louis, Université de Paris, Paris, France

\section{Case 1}

A 41-year-old woman was admitted to the hospital at the mid of the COVID-19 pandemic because of dyspnea, fever, headache, diarrhea, abdominal pain, ageusia, and anosmia that had been ongoing for 17 days. She had a medical history of breast implants and an anal horseshoe abscess and fistula treated surgically 6 months before with non-caseating granuloma found on histological examination. No other infections were reported. Her respiratory rate was $40 / \mathrm{min}$ and $\mathrm{SpO} 2$ was $89 \%$. She received oxygen supplementation. Hydroxychloroquine $(600 \mathrm{mg} /$ day $)$ was started and maintained for 10 days with ceftriaxone and spiramycin as local standard of care. Her nasopharyngeal swab tested positive for SARS-CoV-2. Laboratory tests showed lymphopenia $\left(660 / \mathrm{mm}^{3}\right)$ and elevated C-reactive protein (CRP) at $134 \mathrm{mg} / \mathrm{L}$. Chest CT scan showed extensive infiltrates (50 to $75 \%$ of lungs involved) consistent with severe COVID-19 and a $10-\mathrm{cm}$ right lower mediastinal mass. Two days later, her clinical condition worsened and Boussignac continuous positive airway pressure (CPAP) was started. Control chest CT scan found progression of pulmonary infiltrates without pulmonary embolism. Her

4 Department of Infectious Diseases, Hôpital Saint-Antoine, Assistance Publique Hôpitaux de Paris (APHP), Université de Paris, Paris, France

5 Établissement Français du Sang, INSERM-U955, University Paris-Est-Créteil, Créteil, France

6 Department of Microbiology, Hôpital Diaconesses Croix Saint-Simon, Paris, France

7 Department of Internal Medicine, CHR Annecy-Genevois, Annecy, France

8 CNRS UMR8253, INSERM UMR1151, Institut Necker-Enfants Malades, Université de Paris, Paris, France

9 Laboratory of Immunology, Hôpital Necker-Enfants Malades, Assistance Publique-Hôpitaux de Paris, Paris, France 
condition partially improved, and she was discharged 16 days after admission while maintaining oxygen supplementation of $1 \mathrm{~L} / \mathrm{min}$. At day 41 after first COVID-19 symptoms, she had persistent dyspnea, coughing, and fever $\left(>39^{\circ} \mathrm{C}\right)$ without any evidence of infection besides COVID-19. SpO2 was normal but fell at $88 \%$ after walking just a few steps. Control chest CT scan found partial improvement of pulmonary infiltrates with incipient pulmonary fibrosis, and prednisone was started at $1 \mathrm{mg} / \mathrm{kg}$ (60 mg/day). Her clinical condition momentarily improved, but fever started again after 1 week, with persistent dyspnea. Prednisone was stopped. A bronchoscopy with bronchoalveolar lavage (BAL) was performed without evidence of opportunistic infection but with a positive SARS-CoV-2 PCR. SARS-CoV-2 RNA was still positive in nasopharyngeal swab and was found positive in blood sample. Serologic test for SARS-Cov-2 antibodies was negative. Severe hypogammaglobulinemia was found and confirmed on a frozen serum sample (from day 19 after first symptoms), with absence of B cells (Table 1). Thymoma was confirmed on the biopsy of the mediastinal mass, and a diagnosis of Good syndrome with persistent SARS-Cov-2 infection was made. Because she had persistent fever, an $\mathrm{SpO} 2$ of $96 \%$, and a respiratory rate of $32 / \mathrm{min}$ with oxygen supplementation of $1 \mathrm{~L} / \mathrm{min}$ and elevated CRP $(73 \mathrm{mg} / \mathrm{L})$, a treatment with plasma from COVID-19 convalescent patients was decided. The patient received at day 71 and at day 72 after first symptoms two daily infusions of $200 \mathrm{~mL}$ of plasma from COVID-19 convalescent patients obtained from the "Etablissement Français du Sang." Two plasma units had an anti-SARS-CoV-2 antibody titer of $1 / 160$ and the two others of $1 / 40$. Fever and exertion dyspnea resolved and CRP normalized within 4 days. Nasopharyngeal and plasma SARS-CoV-2 PCR were negative. She was discharged and scheduled for thymectomy and for starting intravenous immunoglobulin replacement therapy.

\section{Case 2}

The patient was a 65 -year-old male with a diagnosis of CVID established at age 33 after presenting with repeated ENT and upper respiratory tract infections and a Campylobacter jejuni infection with concomitant hypogammaglobulinemia and near absence of B cells (Table 1). No infection related to an associated T cell defect was reported. BTK was sequenced and failed to identify any variant in the exons and its flanking regions. No mutations were found for BAFFR, BLNK, CD19, CD79A, CD79B, ICOS, IGHM, TACI, and IGLL1. He also has a significant intellectual disability and a clinical history of surgery for pulmonary artery stenosis in 1964. Secondary causes of hypogammaglobulinemia were excluded. He received monthly immunoglobulin replacement.
In the mid of the COVID-19 pandemic, he presented with asthenia and fever, followed with coughing and dyspnea. Nasopharyngeal SARS-CoV-2 PCR swab was positive. He was hospitalized at day 21 since first symptoms because of a desaturation at $88 \%$. Chest $\mathrm{CT}$ was suggestive of COVID-19 pneumonia. He had persistent fever and CRP was $126 \mathrm{mg} / \mathrm{L}$. Eleven days after admission (day 32 since first symptoms), the patient was transferred to ICU because of respiratory distress. A considerable progression of pulmonary involvement was found on chest CT without evidence of pulmonary embolism. Endotracheal intubation was performed and prone ventilation started. The BAL showed persistent SARS-CoV-2 infection with concomitant Haemophilus influenzae. Treatment with lopinavir/ritonavir was started with broad-spectrum antibiotics. The patient died 19 days after admission (day 40 after first COVID-19 symptoms) of ARDS.

\section{Discussion}

We describe two cases of severe COVID-19 with ARDS in patients with hypogammaglobulinemia and B cell alymphocytosis. One patient died despite mechanical ventilation and one required CPAP. Patient 1 had a concomitant diagnosis of Good syndrome, an acquired immunodeficiency associated with thymoma, whereas patient 2 had a diagnosis of primary hypogammaglobulinemia many years before. To our knowledge, this is the first case of Good syndrome revealed by COVID-19.

Whether primary or acquired ID play a role in the onset of severe COVID-19 is not known. ID might increase the risk of severe disease in case of SARS-CoV-2 infection. COVID-19 occurring in patients with CVID has been reported in 5 patients and seems to confer an increased risk of severe COVID$19[2,3]$. However, previous reports argue that absence of B cells in patients with hypogammaglobulinemia is associated with a mild course of COVID-19 (5/9 patients) which could suggest a role of B cells in the SARS-CoV-2-induced inflammation (Table 2) [2, 4]. Our data provides new evidence suggesting that besides the severity of hypogammaglobulinemia, prolonged B cell depletion could favor chronic severe COVID-19 infection. This is consistent with the key role of $\mathrm{B}$ cells in controlling some viral infections as demonstrated by the chronic enterovirus infections seen in patients with Xlinked agammaglobulinemia (XLA) [5]. As BTK is also expressed in monocytes, dendritic cells, and phagocytic cells [6], additional defects resulting in a more global immune deficiency could be involved in the pathogenesis of chronic enteroviral infections in Bruton's disease. This example raises the possibility of additional defects besides B cell alymphocytosis that might be involved in severe COVID-19 and the clinical course of the disease in patient 2. 
Table 1 Characteristics of immunodeficiency at diagnosis and of COVID-19 viral shedding

\begin{tabular}{|c|c|c|}
\hline & Patient 1 & Patient 2 \\
\hline \multicolumn{3}{|l|}{ Characteristics of ID at diagnosis } \\
\hline \multicolumn{3}{|l|}{ Serum immunoglobulin } \\
\hline $\mathrm{IgG}, \mathrm{g} / \mathrm{L}$ & 3.79 & 1.86 \\
\hline $\operatorname{IgA}, \mathrm{g} / \mathrm{L}$ & 0.27 & $<0.1$ \\
\hline IgM, g/L & 0.18 & $<0.1$ \\
\hline Lymphocyte phenotyping (date) & Day 71 & $04 / 2016$ \\
\hline Lymphocyte, $/ \mathrm{mm}^{3}$ & 1625 & 2400 \\
\hline $\mathrm{T}$ cell $\mathrm{CD} 3+, / \mathrm{mm}^{3}(\%)$ & $1571(97)$ & $1700(70)$ \\
\hline $\mathrm{CD} 4 \mathrm{~T}$ cell $\mathrm{CD} 3+\mathrm{CD} 4+, / \mathrm{mm}^{3}(\%)$ & $700(43)$ & $1200(50)$ \\
\hline Naive & $54 \%$ & $49 \%$ \\
\hline Central memory & $28 \%$ & $19 \%$ \\
\hline Transitional CD45-CCR7-CD27+/CD3 + CD4+ & $6 \%$ & NA \\
\hline Effector & $11 \%$ & $32 \%$ \\
\hline TEMRA & $1 \%$ & NA \\
\hline CD8 T cell CD3 + CD8+, $/ \mathrm{mm}^{3}(\%)$ & $720(44)$ & 400 (17) \\
\hline Naive & $27 \%$ & $46 \%$ \\
\hline Central memory & $3 \%$ & $5 \%$ \\
\hline Transitional & $20 \%$ & NA \\
\hline Effector & $17 \%$ & $50 \%$ \\
\hline TEMRA & $20 \%$ & $30 \%$ \\
\hline $\mathrm{CD} 56+\mathrm{CD} 16+, / \mathrm{mm}^{3}(\%)$ & $50(3)$ & $504(21)$ \\
\hline $\mathrm{CD} 19+, / \mathrm{mm}^{3}(\%)$ & $0(0)$ & $5(0.2)$ \\
\hline $\mathrm{CD} 20+, / \mathrm{mm}^{3}(\%)$ & $0(0)$ & $5(0.2)$ \\
\hline \multicolumn{3}{|l|}{ Mitogen-stimulated $\mathrm{T}$ cell proliferation } \\
\hline Response to PHA stimulation & Normal & NA \\
\hline \multicolumn{3}{|l|}{ SARS-CoV-2-specific $\mathrm{T}$ cell response evaluated by ELISPOT } \\
\hline $\mathrm{S} 1, \mathrm{SFC} /$ million $\mathrm{CD} 3+$ & 893 & NA \\
\hline $\mathrm{S} 2, \mathrm{SFC} /$ million CD3+ & 383 & NA \\
\hline M, SFC/million CD3+ & 1733 & NA \\
\hline $\mathrm{N}, \mathrm{SFC} /$ million CD3+ & 1883 & NA \\
\hline \multicolumn{3}{|l|}{ Positive controls } \\
\hline CEFX Ultra SuperStim pool (JPT), SFC/million CD3+ & TNTC & NA \\
\hline PHA, SFC/million CD3+ & TNTC & NA \\
\hline \multicolumn{3}{|l|}{ Characteristics of COVID-19 viral shedding } \\
\hline \multicolumn{3}{|l|}{ Elapsed time (in days) since first COVID-19 symptoms and } \\
\hline First positive SARS-CoV2 PCR in nasopharyngeal swab & $17(\mathrm{Ct}=31)$ & $5(\mathrm{Ct}=25)$ \\
\hline First positive serum SARS-CoV2 PCR & $64(\mathrm{Ct}=38)$ & NA \\
\hline Last positive SARS-CoV2 PCR in nasopharyngeal swab & $61(\mathrm{Ct}=39)$ & NA \\
\hline Positive SARS-CoV2 PCR in BAL & $64(\mathrm{Ct}=35)$ & $32(\mathrm{Ct}=23)$ \\
\hline First negative SARS-CoV2 PCR in nasopharyngeal swab & 78 & Last PCR still positive \\
\hline First negative serum SARS-CoV2 PCR & 78 & NA \\
\hline
\end{tabular}

$I D$, immunodeficiency; $B A L$, bronchoalveolar lavage; $C t$, cycle threshold; $N A$, not available; ELISPOT, enzyme linked immunoSpot; $S 1$, spike protein peptide pool $1 ; S 2$, spike protein peptide pool 2; $M$, membrane protein; $N$, nucleoprotein; PHA, phytohaemagglutinine; TNTC, too numerous to count
T cell defects have been described in Good syndrome and in CVID patients, clinically or biologically [7, 8], and T cell phenotype of previously reported patients with B cell alymphocytosis and COVID-19 has not been fully addressed
(Table 2). Therefore, additional immunological defects could account for COVID-19 presentations described here but they most likely had a marginal role in our patients due to the following reasons. First, lack of B cells may prevent 


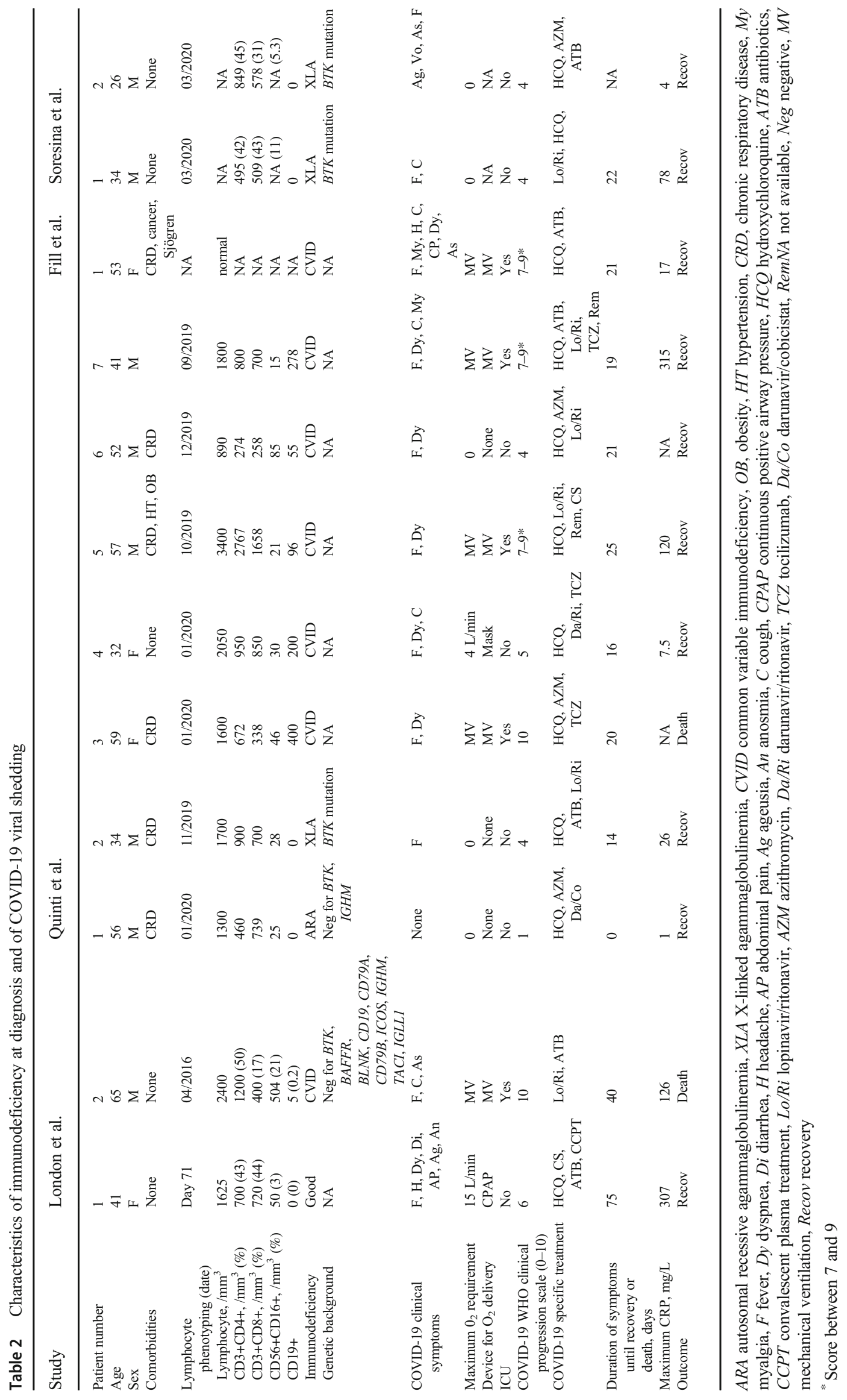


seroconversion and viral clearance as illustrated by the clinical course of patient 1 , whose disease amended with plasma therapy. Moreover, Lacombe et al. reported similar clinical presentations in patients who received B cell depletion therapy using rituximab [9], underlining the role of B cells in seroconversion and viral clearance. Second, chronic enteroviral infections encountered in Bruton's disease can be controlled by intravenous immunoglobulin therapy. Finally, no previous infections related to $\mathrm{T}$ cell defects occurred for either patient, and for patient 1 , the only phenotypic abnormalities found on $\mathrm{T}$ cells were an increase in activated $\mathrm{T}$ cells and an increase in terminally differentiated effector CD8 T cells as often seen in viral infections (Table 1 ). In addition, for patient 2 , mitogenstimulated $\mathrm{T}$ cell proliferation was normal and SARS-CoV-2specific $\mathrm{T}$ cell response evaluated by enzyme-linked immunoSpot (ELISPOT) was positive (Table 1) and similar to what is usually seen in non-ID patients with COVID-19 (data not shown). Altogether, this suggests that B cell defects can play an important role in the development of severe and chronic forms of COVID-19.

Anti-type 1 interferon antibodies could have contributed to severe COVID-19 in patient 1 since patients with Good syndrome are known to develop anti-cytokine antibodies [10] and since anti-type 1 interferon antibodies have recently been described in 10\% of severe COVID-19 patients [11]. Unfortunately, anti-cytokine antibodies were not tested for this patient. The convalescent plasma therapy could have lowered anti-cytokine antibodies in patient 1 as plasma may act by lowering autoantibody levels. Nevertheless, as patient 1 failed to seroconvert, a role in antibody replacement is also highly probable. Moreover, patients receiving repeated administrations of rituximab, a treatment that has been shown to be effective in anti-cytokine disease [12], are prone to develop severe COVID-19 [9]. This supports the role of neutralizing antibodies in convalescent plasma therapy efficacy.

The present observations suggest that patients with persistent B cell alymphocytosis could represent a high-risk population for severe COVID-19 and that this might be due to altered plasma cell generation and ineffective humoral response, as suggested by negative seroconversion. This also shows that treatment with convalescent plasma might be an effective treatment of uncontrolled or prolonged infection with SARS-CoV-2 in patients with persistent B cell alymphocytosis. Further studies are required to confirm efficacy of convalescent plasma in COVID-19 in other settings.

We describe the first two cases of severe COVID-19 in patients with hypogammaglobulinemia and absence of B lymphocytes and of efficacy of convalescent plasma in one patient with prolonged SARS-CoV-2 infection. Further studies are needed to accurately determine if the absence of B lymphocytes contribute to severe COVID-19 onset.
Acknowledgments Marc Garnier, Jérôme Pacanowski, Arsène Mekinian, Christiane Strauss, Elsa Lambrescak, Benjamin Subran, Wladimir Mauhin, Théo Dhôte, Olivier Lidove, Vanina Meyssonnier, Loïc Perrot, Patrick Atienza, Arnaud Vanjak, Laure Bernard, Louise Gillard, Dimitri Kornblum, Denis Debrosse, Justine Wacquet, Lucienne Chatenoud

Author Contributions J.L., D.B., and A. Bérezné wrote the manuscript. J.L., A. Bérezné, V.Z., and A. Baudet contributed to the patient recruitment and management. K.L., F.P., and D.B. discussed the indication for plasma therapy. B.H. performed the SARS-CoV-2 analysis for patient 2 and contributed to the interpretation of the results. A.O. performed the lymphocyte immunophenotyping, the mitogen-stimulated $\mathrm{T}$ cell proliferation, and SARS-CoV-2 ELISPOT and contributed to the interpretation of results. J.L and D.B supervised the project. All the authors reviewed the manuscript.

\section{Compliance with Ethical Standards}

Conflict of Interest The authors declare that they have no conflicts of interest.

\section{References}

1. Collaborative TO, Williamson E, Walker AJ, Bhaskaran KJ, Bacon $\mathrm{S}$, Bates C, et al. OpenSAFELY: factors associated with COVID19-related hospital death in the linked electronic health records of 17 million adult NHS patients. medRxiv. Cold Spring Harbor Laboratory Press; 2020;2020.05.06.20092999.

2. Quinti I, Lougaris V, Milito C, Cinetto F, Pecoraro A, Mezzaroma I, et al. A possible role for B cells in COVID-19? Lesson from patients with agammaglobulinemia. J Allergy Clin Immunol. 2020;146:211-213.e4.

3. Fill L, Hadney L, Graven K, Persaud R, Hostoffer R. The clinical observation of a patient with common variable immunodeficiency diagnosed as having coronavirus disease 2019. Ann Allergy Asthma Immunol 2020;125(1):112-114.

4. Soresina A, Moratto D, Chiarini M, Paolillo C, Baresi G, Focà E, et al. Two X-linked agammaglobulinemia patients develop pneumonia as COVID-19 manifestation but recover. Pediatr Allergy Immunol Off Publ Eur Soc Pediatr Allergy Immunol. 2020;31: 565-9.

5. Bearden D, Collett M, Quan PL, Costa-Carvalho BT, Sullivan KE. Enteroviruses in X-linked agammaglobulinemia: update on epidemiology and therapy. J Allergy Clin Immunol Pract. 2016;4:105965 .

6. Jongco AM, Gough JD, Sarnataro K, Rosenthal DW, Moreau J, Ponda $\mathrm{P}$, et al. X-linked agammaglobulinemia presenting as polymicrobial pneumonia, including Pneumocystis jirovecii. Ann Allergy Asthma Immunol. 2014;112:74-75.e2.

7. Malphettes M, Gérard L, Galicier L, Boutboul D, Asli B, Szalat R, et al. Good syndrome: an adult-onset immunodeficiency remarkable for its high incidence of invasive infections and autoimmune complications. Clin Infect Dis Off Publ Infect Dis Soc Am. 2015;61:e13-9.

8. Malphettes M, Gérard L, Carmagnat M, Mouillot G, Vince N, Boutboul D, et al. Late-onset combined immune deficiency: a subset of common variable immunodeficiency with severe $\mathrm{T}$ cell defect. Clin Infect Dis Off Publ Infect Dis Soc Am. 2009;49:1329-38.

9. Hueso T, Pouderoux C, Péré H, Beaumont A-L, Raillon L-A, Ader F, et al. Convalescent plasma therapy for B-cell depleted patients with protracted COVID-19 disease. Blood. 2020.

10. Burbelo PD, Browne SK, Sampaio EP, Giaccone G, Zaman R, Kristosturyan E, et al. Anti-cytokine autoantibodies are associated 
with opportunistic infection in patients with thymic neoplasia. Blood. 2010;116:4848-58.

11. Bastard P, Rosen LB, Zhang Q, Michailidis E, Hoffmann H-H, Zhang Y, et al. Auto-antibodies against type I IFNs in patients with life-threatening COVID-19. Science. 2020;370:eabd4585.

12. Browne SK, Zaman R, Sampaio EP, Jutivorakool K, Rosen LB, Ding L, et al. Anti-CD20 (rituximab) therapy for anti-IFN- $\gamma$ autoantibody-associated nontuberculous mycobacterial infection. Blood. 2012;119:3933-9.

Publisher's Note Springer Nature remains neutral with regard to jurisdictional claims in published maps and institutional affiliations. 